non-medical scientists, we have insisted that they must be associated with a medical person. But there are all kinds of trials going on in Britain without any ethical sanction-the effects of altering school meals for example.

\section{Auditing New Techniques of Treatment}

CHAIRMAN: Our last topic is perhaps the most difficult-that is, new techniques (such as transplantation) that are risky but solely designed to help the patient. What is the ethical situation about procedures which are pushing the frontiers of medicine away?

DR. EILENBERG: The ethical committee at present is confining itself to an ill-defined area called research. I do not see it taking over a role to monitor the clinical practice of consultants. A consultant who acts in good faith for the patient's benefit, with the consent of the patient and his relatives, is acting within the limits of his responsibility. But this is where the philosophy of Cogwheel and the divisional organization has not been fulfilled-Cogwheel should provide an opportunity to allow a clinical dialogue and mutual criticism of peers within the hospital.

DR. WILliams: I find it difficult to separate these two aspects-if you do two operations of a new type or organ transplant, it's really an experiment.

DR. EILENBERG: But a lot of this is defensible in terms of one's right to practise clinical medicine. There's a danger of setting up administrative bodies to tell doctors what they can and they can't do.

PROFESSOR WITTS: We mustn't inhibit the desire of the inindividual doctor to carry out a new operation or other treatment. But most departments should have some sort of audit.
I think today a senior man can raise a problem of treatment in his division that he couldn't have done thirty years ago.

DR. WILliams: Yes; these issues are raised a lot. The question of heart transplants is a good example. This has been discussed a great deal in various medical committees-some committees have concluded that they should carry on; others that they should stop. Even so, medicine advances by one bright doctor having an idea and pursuing it; we don't want to lose the support for an individual with an idea. But certainly consent of the Cogwheel committee is necessarybecause apart from anything else, this new procedure is likely to make more demands on the nurses, the laboratories and other hospital resources.

CHAIRMAN : What about sanctions against a consultant who goes it alone against the wishes of his fellows?

DR. EILENBERG: Ultimately, the hospital management committee has authority to withdraw facilities-though I'm not saying it's used. But if you create a climate of opinion throughout an institution-a total responsibility by the hospital community-then "mad" acts don't happen. If we don't create some such atmosphere, then the politicians and administrators will step in-and ultimately the patient will be the worse off.

\section{References}

1 British Medical fournal, 1964, 2, 177.

2 Royal College of Physicians of London, Supervision of the Ethics of Clinical Investigations in Institutions. British Medical fournal, 1967 3, 429.

3 British Medical fournal, 1964, 2, 178.

4 Leonard, C. O., Chase, G. A., and Child, B., New England fournal of Medicine, 1972, 287, 423.

5 Ackner, B., Harris, A., and Oldham, A. J., Lancet 1957, 1, 607.

Platt, R., in Ethics in Medical Progress, ed. by G. E. W. Wolstenholme and M. O'Connor, p. 149. London, Churchill, 1966

\title{
Bacterial Resistance: Changing Patterns of Some Common Pathogens
}

\author{
J. E. M. WHITEHEAD
}

British Medical fournal, 1973, 2, 224-228

The growth of drug resistance among bacteria has made several antibiotics useless in treating certain infections for which they were formerly curative. Discoveries of new antibiotics or modifications of existing ones have gained a succession of temporary respites in an otherwise deteriorating situation and have tended to obscure its long-term significance for prescriber and patient. Some authorities, however, consider it

\footnotetext{
Public Health Laboratory, Coventry and Warwickshire Hospital, Coventry

J. E. M. WHITEHEAD, M.B., F.R.C.PATH., Consultant Microbiologist
}

unlikely that any entirely new antibiotic remains to be discovered, ${ }^{1}$ and it is uncertain for how long chemical manipulation of existing antimicrobial drugs will suffice to meet the capacity of bacteria to adapt to them. Those antimicrobials which remain effective must be used wisely therefore-not only in the treatment of individual patients, but also for the ultimate benefit of the community. Sound chemotherapy rests on bacteriological guidance, much of which derives from the continuing observation of the changing patterns of bacterial resistance. This article is concerned with their present trend and its implications for antimicrobial therapy.

\section{Drug Response of Bacteria}

The response of bacteria to chemotherapeutic drugs-the 
commoner ones are classified in the table-may be categorized as susceptible, susceptible (but drug-inactivating), or resistant.

Classification of the Commoner Antibacterial Drugs by Group

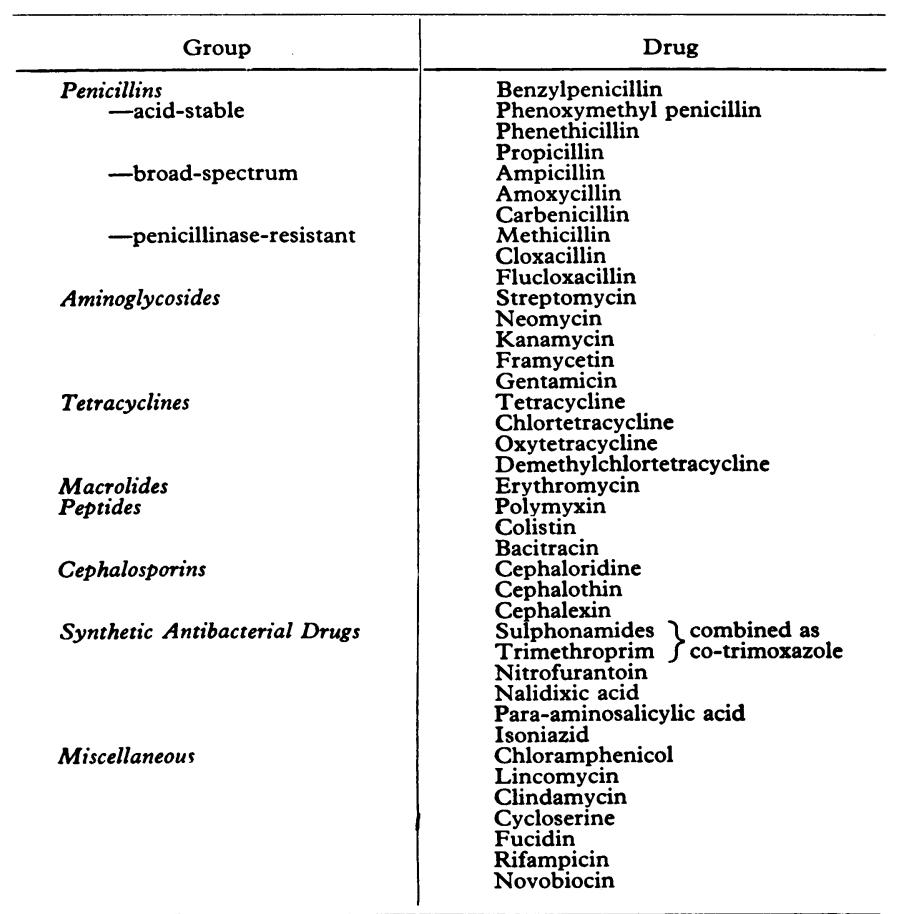

\section{SUSCEPTIBLE}

Exposure of susceptible bacteria to a drug in the concentrations attained by therapeutic dosage may either kill them almost immediately; or, by arresting their multiplication, advance their natural decline. The main bactericidal drugs include the following: penicillin (all types), streptomycin and the other aminoglycosides, polymyxins, fucidin, and co-trimoxazole. The others are usually bacteriostatic, though a few may be bactericidal in high concentrations.

\section{SUSCEPTIBLE (BUT DRUG-INACTIVATING)}

The most important in this category are the penicillinaseproducing staphylococci, the individual cells of which are almost as sensitive as those of staphylococci lacking this enzyme. Some strains of Staphylococcus aureus are more powerful producers of penicillinase than others and are unequivocally resistant. Infections by weak producers may respond to treatment if the number of staphylococci happens to be small and high concentrations of penicillin are attained in the lesion, but for practical purposes they are best regarded as resistant.

Infections by some other penicillinase-producing bacteria may, however, be successfully treated with penicillin if the species is highly susceptible - as is the anthrax bacillus-or moderately susceptible - as are many clostridial species. Inactivation of other antibiotics by bacteria has been described but its contribution to resistance varies in different species and circumstances.

\section{RESISTANT}

Bacteria in this category are generally unaffected by the drug, though in its presence some grow more slowly or with altered morphology, such as small colony variants. Bacteria resistant to one member of a group of antibiotics are usually resistant to the others (cross-resistance), particularly if close chemical relationships exist, as among the various tetracyclines or sulphonamides. Drug dependence is sometimes shown by streptomycin-resistant bacteria.

\section{Acquisition of Resistance}

Originally sensitive bacteria may develop drug-resistance through mutation or may acquire it by one of the processes (described below) necessitating transfer of genetic material from resistant to sensitive organisms.

\section{R-FACTORS TRANSFERRED BY CONJUGATION}

The transfer of resistance by these factors operates principally among the Gram-negative bacilli. Donor and recipient strains which may belong to different species or genera must be closely adjacent to one another-as occurs in the bowelfor conjugation and the transfer of $\mathbf{R}$-factors to take place, and which may be completed in a few minutes. The genetic material thus transferred-plasmid DNA-confers on the recipient strain resistance which is often multiple, sometimes affecting as many as six drugs and possibly more. The recipient strain may act in turn as a donor by transferring resistance to a new recipient. By this means resistance can spread among Gram-negative bacilli, pathogen and nonpathogen alike, in an infectious manner and may result in the acquisition of multiple antibiotic resistance by bacteria which have never been exposed to an antibiotic. Subsequently, however, some of the "infected" bacteria may lose resistance spontaneously.

\section{TRANSFER OF RESISTANCE BY PHAGE (TRANSDUCTION)}

Although drug-resistance among Gram-negative bacilli can also be mediated by phage, most attention has been given to the transfer of resistance by this means (transduction) among staphylococci. When phage from a donor strain of staphylococci resistant to a particular intibiotic initiates infection in a sensitive recipient strain, the transduction (infecting) phage carries with it genetic material in the form of DNA, which confers resistance to the antibiotic on the recipient. Unlike that transferred by $\mathrm{R}$-factors, resistance to one or two antibiotics only is conferred at a time. Acquisition of resistance by transduction is influenced by the phage groups to which the staphylococci belong. It is more readily achieved if the strains belong to the same group than if they belong to different groups. Nevertheless, between strains of either groups I or III and those of group II it fails. ${ }^{2}$ Antibioticresistant staphylococci found in hospital acquired infections are frequently typable by phages of groups I and III, whereas few antibiotic-resistant strains are typable by group II phages. Probably transduction by phage has played a part in the emergence of the antibiotic resistant "hospital" strains of Staph. aureus.

\section{OPERATION OF SELECTION PRESSURE}

Drug-resistant organisms may arise in a population of drugsensitive bacteria by mutation or by one of the processes of genetic transfer. Because it does not affect their survival and multiplication, exposure of the population to the particular drug permits the drug-resistant few to supplant the susceptible majority. The resistant bacterial population which emerges by this selective pressure remains resistant in the absence of the selecting drug so that, in any new infections to which its members may give rise, resistance is present from the outset. Nevertheless, it may not endure in every strain acquiring it, for the continued absence of the drug may eventually permit the sensitive state to become re-established. 
The rate of increase of resistance varies widely, so that during treatment with some antibiotics-for instance, streptomycin - a high degree of resistance may develop in the course of one or two days in a single step, whereas with many others resistance emerges more gradually in small incremental steps. To a few antibiotics-for example, the polymyxins-susceptible bacteria fail to develop significant resistance, nor have some bacterial species yet been shown to acquire resistance in vivo to certain antibiotics, as is well exemplified by the continuing susceptibility of haemolytic streptococci and pneumococci to penicillin despite more than a quarter of a century of use-though recently pneumococci relatively insensitive to penicillin have been reported. ${ }^{3}$

Bacterial resistance to chemotherapeutic agents may be met with during the treatment of individual patients. In some it may emerge in the infecting strain in one of the ways described earlier, or, as more usually happens, the infecting strain is eliminated from the unhealed lesion before resistance develops and is replaced by resistant organisms, usually of a different species, from another site in the body or surroundings of the patient. These may be either naturally drugresistant species or drug-resistant variants of formerly sensitive strains which, because of the selection pressure created by sustained use of the drug, have become prevalent in the particular environment.

\section{Resistance Patterns}

Knowledge of the current drug-resistance patterns of common pathogenic bacteria is useful in clinical practice, for in most cases antibiotic therapy has to be begun in the absence of the results of sensitivity tests on the infecting organisms. Without a bacteriological diagnosis the identity of the probable causative pathogen can only be guessed, and the antimicrobial drug has to be chosen according to, among other considerations, the likely drug resistance pattern of the particular bacterial species. Unfortunately, these patterns are not constant, but vary with time, place, and environment. Most medical laboratories engaged in diagnostic bacteriology monitor, to a varying extent, the antibiotic resistance patterns of the pathogens they isolate. In hospital, therefore, guidance may be expected from the microbiologist about the patterns to be expected in a given bacterial species within a particular ward or unit. At the same time the need for specimens collected before or simultaneously with the initiation of therapy will probably be emphasized, so that the opportunity to identify and determine the sensitivity of the infecting bacteria is not lost. Outside hospital, general practitioners and others may look to their local laboratory for similar information about the pathogens prevalent in the area.

Besides the variations encountered at different periods and in different localities, the environmental background of the patient may also have much to do with the resistance patterns likely to be found in the bacteria infecting him. Knowledge of this can be useful on occasions, for resistant strains are met with more commonly in occupations and surroundings in which antibiotics are used or handled. Hosvitals, health centres, surgeries, (medical, veterinary, and dental) pharmacies, and sections of the pharmaceutical industry, farms, and parts of the animal feeding-stuff industry are examples of surroundings which may contribute resistant bacteria to those who work in them or who are otherwise closely connected with them.

\section{TRENDS OF RESISTANCE}

\section{Staphylococci}

Although Staph. aureus may be considered still to be the commonest cause of pyogenic infections, Gram-negative bacilli have attained equal importance within hospitals.

Outside hospitals penicillin-sensitive staphylococci are still frequently met with but inside hospitals penicillin-resistant strains predominate. Resistant strains produce penicilenase and are thus able to tolerate not only penicillin but ampicillin and carbenicillin also. Among penicillin-resistant staphylococci are a variable proportion of strains which are resistant to other antibiotics besides, notably streptomycin, tetracycline, erythromycin, novobiocin, and chloramphenicol. Such strains which usually belong to phage groups I and III are sometimes referred to as "hospital" staphylococci, and show an appreciable proclivity to cause sepsis.

Also linked with multiple resistance is the ability to produce large amounts of penicillinase. ${ }^{4}$ The development of semi-synthetic penicillins stable to staphylococcal penicillinase-methicillin, cloxacillin, and flucloxacillin-with which to combat these organisms, provided a clear example of the temporary respite referred to previously: when first introduced a valuable therapeutic advantage was gained over the bacterial species which had endangered patients in hospital during the late fifties, but it was to be shortlived. Slowly at first and then more rapidly, the proportion of methicillin-resistant staphylococci has increased in hosnitals. From less than $1 \%$ of strains in 1960 , it had risen by 1968 to $2.63 \%$ and by 1969 to $4 \cdot 11 \%$ of all strains received from British sources for phage-typing at the Central Public Health Laboratory. ${ }^{5}$ But more startling increases have been reported from other countries and from certain localities-for example, in Newcastle the incidence rose from $35 \%$ in 1969 to $58 \%$ in the first half of $19700^{6}$

Widespread use of penicillinase-stable penicillins is not, however, a prerequisite for the emergence of methicillin resistance among staphvlococci, for methicillin-resistant strains have been detected in relative abundance in hospitals and places where the drug had never been used, and it is thought that its increasing incidence may be related to the greatly increased consumption of the other penicillins in recent years. ${ }^{5}$ These staphylococci are also resistant to cephalosporins and the treatment of severe infections may require the use of certain antibiotics-ervthromycin clindamycin, novobiocin, fucidin, and rifampicin-to which Staph. aureus develops resistance readily when they are administered singly. Alternatives may be found in gentamicin, co-trimoxazole, or in various combinations of antibiotics. ${ }^{7}$

Resistance to neomycin-and with it, cross-resistance to kanamvcin and framycetin-is another development among hospital staohvlococci during the past decade, and is sometimes associated with resistance to bacitracin. Resistance to these drugs calls into question their use in the many sprays, creams, and powders which contain these and other antibiotics, in attempting to prevent and treat superficial infections by staphvlococci. It is also relevant to artempts at suppression of nasal carriage by application of creams containing these antibotics, for these may lead to the dissemination of resistant strains; $2 \%$ hexachlorophane cream may be used instead, ${ }^{8}$ but with due regard to its possible toxicity.

\section{Streptococci and Pneumococci}

Any constraints on the use of penicillin in the treatment of haemolytic streptococcal infections are imposed paradoxically enough, not by the development of drug resistance in the bacteria-they remain highly penicillin-sensitive-but by the growing number of persons who have become hypersensitive to this antibiotic.

For them an alternative is erythromycin and resistance to it among haemolytic streptococci is exceedingly rare so far. Twenty years ago the same could have been said of tetracycline resistance, but today about one-third of strains are resistant. Nor is it restricted to the hospital setting as at the time of its first reported occurrence in the United Kingdom, ${ }^{9}$ but has since become well established among strains in the community outside ${ }^{10}$ - helped perhaps by the long perind during which the tetracyclines were the main "broadspectrum" antibiotics available for giving by mouth. The incidence of resistant strains in a locality is not steady but fluctuates over periods of months.

Pneumococci are akin to haemolytic streptococci in their resistance patterns, except that tetracycline resistance has been a later and more localized development. In Liverpool, for instance, the reported incidence of tetracycline-resistant pneumococci in patients outside hospital rose from $7 \%$ in 1967 to $12 \%$ in 1968, 
whereas in Coventry during the same period the incidence remained below $1 \%$.

Streptococcus faecalis is distinguished from the other streptococci by relative resistance to many of the antibiotics to which they are susceptible. It is only moderately sensitive to penicillin, but slightly more so to ampicillin, and rather more than half the strains are tetracycline resistant. It is inherently sulphonamide resistant.

\section{Neisseriae}

The abandonment of sulphonamides for the treatment of gonorrhoea was an early instance of the failure of a major antibacterial drug owing to the selection and spread of naturally resistant strains.

Penicillin seems destined to become another, for as gonococci have gradually become less sensitive to it, so the dose required to achieve acceptable rates of cure has had to be raised to near the practicable limit. In 1958 a large multicentre survey showed that $13 \%$ of strains were then relatively insensitive to penicillin ${ }^{12}$; ten years later a smaller study in a London hospital found that the proportion insensitive had reached between $35 \%$ and $40 \% .{ }^{13}$ Gonococci insensitive to penicillin are usually, but not always, resistant to streptomycin, and less frequently to erythromycin. Tetracyclines are still active against most strains in Britain-the opposite is the case in the U.S.A.- and most are susceptible to the synergic effect of varying combinations of trimethoprim and sulphonamides.

The last ten years have seen a remarkable growth of sulphonamide resistance among meningococci in some countries-in particular, the U.S.A., where the incidence is reported as rising from $28 \%$ in 1964 to $39 \%$ in $1966^{14}$ and to $70 \%$ in 1969.15 By comparison, the incidence of $4.1 \%$ observed in Great Britain in 1966-8 is low. ${ }^{16}$ Nevertheless, as sulphonamide-resistant strains become more common, greater reliance is placed on penicillin and ampicillin in treatment and it is a matter for gloomy speculation that meningococci will eventually, like the gonococci, become increasingly tolerant of penicillin.

\section{Mycobacterium tuberculosis}

In countries where adequate facilities for the diagnosis, treatment, and control of tuberculosis exist, the spread of drugresistant strains has been kept within bounds. In Britain the incidence of drug-resistant tubercle bacilli in new cases of pulmonary tuberculosis has remained unchanged at about $4.5 \%$ for the past 17 years, but the rates among Asian immigrants are higher. ${ }^{17}$

\section{Gram-negative Bacilli}

Resistance patterns among the bacteria comprising this large and complex group are to a great extent determined by the operation of infectious drug resistance, but not to the complete exclusion of other processes by which resistance may emerge. In hospitals, for instance, those bacteria with more extensive natural resistance to the commonly used antibiotics have been selectively favoured and hospital-acquired infections by species of Pseudomonas, Klebsiella, and Proteus have become all too common. But resistance, of ten multiple and determined by R-factors, has appreciably increased among salmonellas, shigellas and the enteropathogenic types of Escherichia coli and is now common also among normal bowel bacteria from which coliform infections of the urinary tract and other parenteral tissues may originate. ${ }^{18}$ The scale of the increase among some intestinal pathogens may be gauged from two examples.

Shigella sonnei, the commonest shigella in this country, has been shown to possess transferable resistance..$^{19}$ Observations on strains from the London area showed that, in $1961,4 \%$ of isolates were resistant to streptomycin and 5\% to tetracyclines. In 1969 the figures had risen to $70 \%$ and $42 \%$, respectively. By 1969 , moreover, $94 \%$ of strains were resistant to ampicillin and more than $70 \%$ were resistant to at least three drugs, the commonest being ampicillin, sulphonamides, and streptomycin. ${ }^{20}$ However, in this as in other simple infections of the bowel not involving systemic disease, treatment with antibiotics is not normally required.

In Salmonella typhimurium, the commonest of the salmonella serotypes infecting man and animals, a substantial increase in the frequency of drug resistance was noted among the many strains from human and animal sources monitored at the Enteric Reference Laboratory during 1961-5, when the incidence rose from $2.9 \%$ to $61 \%$. It was greatest-nearly $100 \%$-among strains of type 29 and took place first in infections among calves reared by intensive farming methods, but quickly spread to man, causing over 500 infections and six deaths. The multiple resistance was transferable. ${ }^{11}$

The evidence in this epidemic pointed to the bowel flora of farm animals as the point of origin of the infectious drug resistance, but this form of resistance is now frequently present among human enterobacteria, especially in children. Drug-resistant coliform bacteria were found in $81 \%$ of healthy children under 2 years old in Dublin ${ }^{22}$ and in $67 \%$ of those under 5 years old in the Bristol area..$^{23}$ The incidence among normal adults in the Bristol area was $46 \%$-closely similar to that of $52 \%$ found in London patients awaiting non-urgent surgery. ${ }^{18}$ The Bristol survey, however, (made before the implementation of the Swann report ${ }^{24}$ on the use of antibiotics in animal feeding stuffs could have taken effect) showed a higher incidence among rural adults in occupational contact with farm animals (63\%) than in those with other occupations (29\%).

A further study in the same city, based on sampling coliform bacilli from the sewage emanating from a large general hospital and a nearby housing estate, showed the proportion of drugresistant strains to be seven times greater in the hospital than in the housing-estate effluent, and that the $R$-factors from the hospital bacteria frequently specified resistance to a wider range of antibiotics than did those from the bacteria of the housingestate sewage. ${ }^{25}$ The proportion of resistant strains able to transfer their resistance has, in most studies, ranged between one-half and two-thirds.

The relevance to clinical practice of the prevalence and spread of R-factors among Gram-negative bacilli is twofold. Firstly, the spectrum of resistance they convey drastically curtails the choice of antibiotics suitable for treating the infections-urinary tract, wounds, bloodstream, and (by the enteropathogenic types of Esch. coli) infantile gastroenteritisto which these bacteria give rise. Datta and her colleagues studied 429 infections of various kinds due to coliform bacteria other than Pseudomonas aeruginosa (pyocyanea), which occurred in a general hospital during 1970, and showed that $43 \%$ were due to drug-resistant strains, and that the resistance was frequently multiple and determined by $R$-factors. ${ }^{23}$ Though the extent of the resistance patterns limited the choice, in vitro sensitivity tests showed that in every case there still remained at least one antibacterial drug likely to prove effective. These findings make clear how relevant these tests are for guiding antibacerial therapy in these infections.

Secondly, as is apparent from the recent typhoid epidemic in Mexico, resistance to chloramphenicol may be acquired by epidemic strains of $S$. typhi by this means ${ }^{27}$-with evident consequences for the prognosis of patients suffering from a serious disease in which the main antibacterial drug is no longer effective.

\section{Abating Selection Pressure}

The prevalence of drug-resistant, R-factor carrying bacteria is regarded by Richmond as the bacterial response to the selection pressures exerted on them in their various habitats by the weight of antibiotics administered in medical and veterinary practice-environmental consequences of the use of antibiotics succinctly expressed in the subtitle of his Stenhouse-Williams lecture as "what goes up must come down."25 The extent to which the selection pressure generated by veterinary usage contributes to the bacterial resistance encountered in human disease is uncertain, except in circumstances such as the $S$. typhimurium episode previously referred to. Nevertheless, in 1967, as the Swann report dis- 
closed, the antibiotics used for veterinary purposes amounted to nearly two-thirds of those used in human medicine. The legislation resulting from the report should ensure that, in respect of antibiotic supplementation of animal feeding-stuffs at least, medically useful antibiotics no longer contribute to the selection pressures which this practice creates.

In the human milieu the most intense pressures resulting from antibiotic use are to be found in hospitals. The consequent accumulation of drug-resistant strains within them has demanded more stringent measures to prevent the spread of hospital-acquired infection, but they are insufficient in themselves to obviate the hazard which these strains hold for patients. Ways of reducing selection pressures have had to be sought, therefore, by adopting antibiotic policies, which regulate the use of antibiotics in a particular hospital or unit. Policies vary, some requiring complete withdrawal of one or more antibiotics from current use, others restricting use to specified infections or requiring use in combination or rotation. To be effective a policy must be specially devised to fit the requirements of a local situation and its particular resistance patterns-for what is applicable in one hospital, or in one ward, may not apply in another. Two recent examples serve to illustrate the encouraging results which may be achieved through their use.

Ps. aeruginosa highly resistant to carbenicillin appeared and spread in a burns unit, the resistance probably having been acquired by $R$-factor transfer from other enterobacteria. This particular R-factor also determined resistance to tetracycline, kanamycin, ampicillin, and cephaloridine and was frequently present in the enterobacteria isolated from the burns. When the use of carbenicillin was stopped, carbenicillin-resistant strains of Ps. aeruginosa disappeared from the unit, only to re-emerge when carbenicillin was again administered to a patient. A survey showed that bacteria carrying this $\mathbf{R}$-factor were scarce in the hospital environment and absent from the stools of the staff. The prohibition was then widened to include the other four drugs as well as carbenicillin. Carbenicillinresistant Ps. aeruginosa again disappeared and the unit also remained free of the enterobacteria carrying the R-factor for at least three months. ${ }^{26}$

Infections by Klebsiella aerogenes had reached epidemic proportions in a neurosurgical unit in which ampicillin and cloxacillin had been used heavily for some years, often in prophylaxis. Colistin was resorted to, but with less and less effect, so that eventually the use of all antibiotics in the unit was stopped. Thereupon the outbreak was brought to an end and infections by other bacteria declined also. Subsequently, when antibiotic therapy was emoloyed in the unit it was guided not by the mere isolation of a pathogen, but by the patient's clinical state, preference being given to narrow-spectrum rather than broad-spectrum drugs. ${ }^{27}$

Well thought-out policies-applied in specialized and relatively self-contained units with close bacteriological surveillance-may be expected to achieve further successes of this kind, which may lead in time to a more general reappraisal of the use of antibiotics-particularly in prophylaxis.
In large general hospitals the framing of antibiotic policies likely to prove effective is complicated by the very diversity of the infections, staff, and procedures which they encompass, but worthwhile gains have been recorded after their introduction to combat the rising incidence of a particular pathogenfor example, multiple antibiotic-resistant Staph. aureus. ${ }^{23}$

Indiscriminate prescribing of antibiotics, whether inside or outside hospitals, adds needlessly to the mounting pressures for selection of resistant organisms. It may seem an overstatement to describe it as an act of environmental pollution, but when the full and ultimate consequences of this manner of use are grasped it is less of an exaggeration than might at first appear. What makes for rational chemotherapy is the prescribing of antibacterial drugs only where there are valid clinical indications and when attention is paid to the current resistance patterns of the probable pathogens.

This article is based on a lecture given in the Birmingham course under the title "The Scientific Basis of Clinical Practice" (see B.M.f., 27 November 1971, p. 510).

\section{References}

1 Garrod, L. P., and O'Grady, F., Antibiotic and Chemotherapy, 3rd ed., p. 10. London, Livingstone, 1971.

2 Macdonald, S., Lancet, 1966, $2,1107$.

3 Hansman, D., Glassow, H. N., Sturt, J., Devitt, L., and Douglas, R. M., Nature, 1971, 230, 407.

4 Richmond, M. H., Parker, M. T., Jevons, M. P., and John, M., Lancet, 1964, 1, 293.

5 Parker, M. T., and Hewitt, J. H., Lancet, 1970, 1, 800.

6 Hale, J. H., and Selkon, J. B., Lancet, 1970, $2,528$.

7 Brumfitt, W., and Percival, A., Lancet, 1971, 1, 387.

8 Noone, P., Griffiths, R. J., and Taylor, C. E. D., Lancet, 1970, 1, 1202.

$\because$ Lowbury, E. J. L., and Cason, J. S., British Medical fournal, 1954, 2, 914.

10 Mitchell, R. G., and Baber, K. G., Lancet, 1965, 1, 25.

${ }_{11}$ Percival, A., Armstrong, E. C., and Turner, G. C., Lancet, 1969, 1, 998.

12 Medical Research Council Report, Lancet, 1961, 2, 226.

13 Philips, I., Rimmer, D., Ridley, M., Lynn, R., and Warren, C., Lancet, $1970,1,263$.

14 Wiggins, G. L., and Schubert, J. H., Bacteriological Proceedings, 1967, p. 96.

Artenstein, M. S., New England fournal of Medicine, 1969, 281, 678.

Abbott, J. D., Adams, D., and Collins, T. J., fournal of Medical Microbiology, 1970, 3, 233 .

17 Springett, V. H., British Medical fournal, 1972, 1, 422

18 Dringett, V. H., British Medical fournal, 1972,1

19 Davies, J. R., Farrant, W. N., and Tomlinson, A. J. H., fournal of Hygiene, 1968, 66, 479 .

${ }^{20}$ Davies, J. R., Farrant, W. N., and Uttley, A. H. C., Lancet, 1970, 2, 1157.

21 Anderson, E. S., British Medical fournal, 1968, 3, 333.

22 Moorhouse, E. C., British Medical fournal, 1969, 2, 405

${ }^{23}$ Linton, K. B., et al., Fournal of Hygiene, 1972, 70, 99.

${ }^{24}$ Department of Health and Social Security, Report of the foint Committee on the Use of Antibiotics in Animal Husbandry and Veterinary Medicine. London, H.M.S.O., 1969.

${ }^{25}$ Richmond, M. H., fournal of Applied Bacteriology, 1972, 35, 155.

${ }^{26}$ Lowbury, E. J. L., Babb, J. R., and Roe, E., Lancet, 1972, 2, 941.

${ }_{28}^{27}$ Price, D. J. E., and Sleigh, D. J., Lancet, 1970, 2, 1213. 